\title{
Potential Drug Interactions and Drug Risk during Pregnancy and Breastfeeding: An Observational Study in a Women's Health Intensive Care Unit
}

\section{Interações medicamentosas potenciais e risco de medicamentos durante a gravidez e amamentação: um estudo observacional em unidade de terapia intensiva}

\author{
Amanda Canato Ferracini ${ }^{1}$ Aline Teotonio Rodrigues ${ }^{1}$ Marília Berlofa Visacri ${ }^{1}$ Rebeca Stahlschmidt ${ }^{1}$ \\ Nice Maria Oliveira da Silva ${ }^{2}$ Fernanda Garanhani Surita ${ }^{1}$ Priscila Gava Mazzola ${ }^{3}$ \\ 1 Faculty of Medical Sciences (FCM), Universidade Estadual de \\ Campinas, Campinas, São Paulo, Brazil \\ 2 Pharmacy Service of Women's Hospital Professor Doutor José \\ Aristodemo Pinotti, Centro de Atenção Integral à Saúde da Mulher \\ (CAISM), Universidade Estadual de Campinas, Campinas, São Paulo, \\ Brazil \\ ${ }^{3}$ Faculty of Pharmaceutical Sciences (FCF), Universidade Estadual de \\ Campinas, Campinas, São Paulo, Brazil \\ Address for correspondence Amanda Canato Ferracini, MSc, \\ Faculdade de Ciências Médicas (FCM), Universidade Estadual de \\ Campinas, Alexander Fleming, 105, Zip Code 13083-881, Campinas, \\ SP, Brazil (e-mail: amanda.cferracini@gmail.com).
}

Rev Bras Ginecol Obstet 2017;39:258-264.

\section{Abstract \\ Keywords \\ - intensive care unit \\ - potencial drug interactions \\ - pregnancy \\ - breastfeeding \\ - patient safety}

Introduction In the pregnancy-puerperal cycle, women may develop complications that require admission to the Intensive Care Unit (ICU). Thus, special attention to pharmacotherapy is necessary, particularly to potential drug interactions (PDIs) and to the effect of the drugs on the fetus and newborn.

Objective The aim of this study was to determine the profile of PDIs and the potential risk of drugs used during pregnancy and breastfeeding among patients admitted to the ICU.

Methods We conducted an observational, cross-sectional and prospective study, including pregnant and breastfeeding women admitted to the ICU at the Women's Hospital of a university in the city of Campinas, Brazil, for one year. Online databases were used to identify and classify the PDIs and the potential risk of the drugs used during pregnancy and breastfeeding.

Results We evaluated 305 prescriptions of 58 women, 31 pregnant and 27 breastfeeding, and 284 (91\%) prescriptions presented PDIs. A total of 175 different combinations of PDIs were identified in the prescriptions, and adverse effects caused by the simultaneous use of drugs were not actually observed in the clinical practice. A received

October 21, 2016

accepted

March 13, 2017

published online

June 1, 2017
DOI https://doi.org/

$10.1055 / \mathrm{s}-0037-1603680$. ISSN 0100-7203.
Copyright $\odot 2017$ by Thieme Revinter

Publicações Ltda, Rio de Janeiro, Brazil
License terms

(c) (i) $\ominus$ (\$) 


\section{Resumo}

Palavras-chave

- unidades de terapia intensiva

- interações medicamentosas potenciais

- gravidez

- amamentação

- segurança do paciente total of 26 (1.4\%) PDIs were classified as contraindicated. We identified 15 (13.8\%) drugs prescribed with risk $D$, and $2(1.8 \%)$ with risk $X$ for pregnant women, as well as 4 (4.9\%) drugs prescribed with high risk for breastfeeding women.

Conclusions This study demonstrates that there is a high incidence of PDIs in prescriptions. Most drugs used by pregnant and breastfeeding women at the ICU did not present serious risks to their fetus and newborns, but sometimes drugs with risk $\mathrm{D}$ or $\mathrm{X}$ are necessary in the course of the treatment.

Introdução No ciclo gravídico-puerperal, as mulheres podem desenvolver complicações que necessitam de internação na Unidade de Terapia Intensiva (UTI). Assim, é necessária uma atenção especial à farmacoterapia, particularmente às interações medicamentosas potenciais (IMPs) e ao risco dos medicamentos para o feto e o recémnascido.

Objetivo Determinar o perfil das IMPs e o risco potencial dos medicamentos utilizados durante a gravidez e a amamentação entre as mulheres internadas em UTI. Métodos Foi realizado um corte transversal e prospectivo, observacional, incluindo mulheres grávidas e lactantes internadas na UTI do Hospital da Mulher de uma universidade de Campinas durante um ano. Bases de dados online foram usadas para identificar e classificar as IMPs e o potencial risco de uso de medicamentos durante a gravidez e a amamentação.

Resultados Foram avaliadas 305 prescrições de 58 mulheres, 31 grávidas e 27 lactantes, e 284 (91\%) prescrições apresentaram IMPs, sendo que 175 combinações diferentes de IMPs foram identificadas nas prescrições, e não foram observados efeitos nocivos pelo uso concomitante dos medicamentos na prática clínica. Um total de 26 $(1,4 \%)$ IMPs foram classificadas como contraindicadas. Foram identificados $15(13,8 \%)$ medicamentos prescritos com risco D, e $2(1,8 \%)$ com risco X para mulheres grávidas, e foram identificados 4 (4,9\%) medicamentos prescritos como de alto risco para as mulheres que estavam amamentando.

Conclusões Este estudo demonstra que há uma alta incidência de IMPs nas prescrições. A maioria dos medicamentos utilizados por mulheres grávidas e lactantes em UTI não apresentou sérios riscos para o feto e o recém-nascido, mas às vezes são necessários medicamentos categorizados como risco D ou X.

\section{Introduction}

In women's health care, special attention is required during the pregnancy-puerperium cycle, when a woman can develop several obstetric and non-obstetric complications that can require admission to an Intensive Care Unit (ICU). ${ }^{1-5}$

During hospitalization, pregnant and breastfeeding women use a complex pharmacotherapy with many drugs prescribed, leading to potential drug interactions (PDIs). Potential drug interactions are defined as pharmacological or clinical responses to the administration of two or more drugs, which is different from the response when these agents are used individually. ${ }^{6}$ Due to the highly complex environment of the ICUs and to the great number of medications that most critical patients need, their prescriptions are more susceptible to have potential drug-drug interactions. ${ }^{7}$ A study conducted by Plaza et $\mathrm{al}^{8}$ showed that $23 \%$ of clinically significant adverse events observed in a studied ICU in Chile were related to drug interactions.
The use of drugs during pregnancy calls for special attention because it may result in damage to the mother and the fetus. In order to avoid undesirable side effects, especially in the first trimester, the appropriate selection of drugs according to the gestational age is required. Reducing medication errors and improving patient safety are the important areas of discussion here. ${ }^{9,10}$

Risk evaluation of the drugs used during breastfeeding in postpartum patients admitted to the ICU requires knowledge of the factors that determine if a medication is safe to be used during this period, such as lipid solubility, the ability to bind protein, the level of ionization, the half-life, and the bioavailability of these drugs. These concepts are relevant because some drugs are excreted in the breast milk and therefore may cause problems to the newborn. ${ }^{9-14}$

The aim of this study was to determine the profile of PDIs and the risk categorization of the drugs used during pregnancy and breastfeeding found in the prescriptions of the women admitted to an ICU specialized in women's health. 


\section{Methods}

\section{Study Design and Participants}

We conducted a prospective cross-sectional study in the ICU at the Women's Hospital of a university in the city of Campinas, Brazil, a referral center in women's health. This ICU has 6 adult beds, and serves acutely ill women with obstetric, gynecological, and oncological morbidities who require intensive life support. This ICU has a multidisciplinary team composed of members from different healthcare professions, such as physicians, nurses, pharmacists, physiotherapists, psychologists and nutritionists. Pregnant or breastfeeding women over 18 years old admitted to the ICU from Monday to Friday were included. Women in the postpartum period, non-breastfeeding, and patients who were admitted to the ICU and discharged on weekends were excluded from the study.

\section{Data Collection Procedures}

Electronic prescriptions of the patients throughout the course of one year (from October 2012 to September 2013) were evaluated through the computerized system that stores data, enabling the search by the date of the prescriptions and the inpatient unit (one prescription was evaluated per day of hospitalization, per patient). Patient data comprised of identification (number of hospital record); age (in years); number of prescriptions; name of each drug prescribed; number of units prescribed; and average number of drugs per prescription. The PDIs and the risk categorization of the drugs during pregnancy and breastfeeding found in the prescriptions were quantified and classified.

For the identification and classification of the PDIs, an interactive system called DrugReax System was used. This system is part of the international database called Thomson Micromedex. To use this system, each generic name of the drugs prescribed must be entered in the system. ${ }^{15}$ The system returns with a drug-drug combination showing the interactions. The severity of each interaction is classified as secondary, moderate, important and contraindicated ("secondary" interactions generally do not require a major intervention in the treatment, and "contraindicated" indicates that the drugs are contraindicated for concomitant use). Its most likely mechanism is a review of the documentation regarding this drug interaction, onset and the available literature. ${ }^{15}$ The therapeutic classes and affected organs involved in the PDIs were classified according to the first level of the Anatomical Therapeutic Chemical (ATC) Classification System. ${ }^{16}$

To analyze the risk of the drugs to the pregnancy, the classification of the Food and Drug Administration (FDA) was adopted. It consists of five categories: A, B, C, D and X; A is the safest, and $X$ is absolutely contraindicated. ${ }^{17}$ The risk of the drugs ingested by a newborn through breastfeeding was consulted in the database called E-lactancia.org. ${ }^{18}$ The risk in this database is categorized as "very low risk," "low risk," "high risk" and "very high risk"; "very low risk" is the safest category, and "very high risk" is absolutely contraindicated.
Furthermore, this database shows alternatives to the patients' drug therapy, enabling rapid decision when choosing a safe medication. ${ }^{18}$

\section{Data Processing and Analysis}

The PDIs and the risk of specific drugs during pregnancy and breastfeeding were estimated and classified in spreadsheets using the Microsoft Excel (Microsoft, Redmond, WA, US) software, so all data was tabulated and analyzed. The descriptive analysis to evaluate the frequencies ( $\mathrm{n}$ ) and percentages (\%) for the categorical variables and the descriptive statistics for the numeric variables were performed. The total of PDIs, the risks of the drugs and their severity, and the average of the prescribed drugs during the hospital stay, all for each patient, were calculated and evaluated to establish the prevalence of the PDIs and the risk of using specific drugs during pregnancy and breastfeeding. The present study was approved by the Research Ethics Committee of the institution (CAAE: 1187.0.146.000-11). The present study followed the checklist research of the strengthening the reporting of observational studies in epidemiology (STROBE) statement. ${ }^{19}$

\section{Results}

Demographic Characteristics and Profile Prescriptions During the period from October 2012 to September 2013, 58 patients were admitted to the ICU; 31 pregnant and 27 breastfeeding women. The average age was $30.2 \pm 6.0$ (average \pm standard deviation [SD]; between 19 and 46 years old); the number of days in the ICU was $5.3 \pm 9.1$, with a range one of 1 to 58 days of stay; and 1 patient died in the postpartum period of uncontrolled systemic lupus erythematosus.

The most common reasons for admissions were: hypertensive disorders (69.0\%), post-operative postpartum (23.2\%), and sepsis (7.8\%). A total of 34 patients had no comorbid conditions; 17 patients showed 1 comorbid condition, and 7 patients had more than 1 comorbid conditions. - Table 1 demonstrates the demographic characteristics of the study population.

We evaluated 305 prescriptions (200 for pregnant women and 105 for breastfeeding women), with a mean of $5.7 \pm 9.1$ prescriptions per patient. A total of 138 different drug types were prescribed, with an average of $13.9 \pm 3.2$ drugs per prescriptions. The most prescribed drugs for the pregnant women were: dipyrone, enoxaparin and hydralazine (6.5\%, $5.9 \%$ and $3.7 \%$ respectively). For the breastfeeding women, the most prescribed drugs were: dipyrone, enoxaparin and simethicone (7.2\%, $5.9 \%$ and $4.4 \%$, respectively).

\section{Potential Drug Interactions}

Among the 138 different drugs prescribed, 97 drugs (70.3\%) were involved in at least one PDI, and 284 (91\%) prescriptions had PDIs, totalizing 1,849 PDIs in all prescriptions ( $6.0 \pm 5.7$ per prescription), with a range of 1 to 17 PDIs. Among the PDIs found in this study, 850 were moderate (632 [47.1\%] for the pregnant women, and 218 [42.8\%] for the breastfeeding women); 589 were important (497 [29.6\%] for the pregnant women, and 192 [37.8\%] for the breastfeeding women); 384 
Table 1 Demographic characteristics of the study population

\begin{tabular}{|l|l|}
\hline Characteristics & No. (\%) \\
\hline Patients & 58 \\
\hline Pregnant women & $31(53.5)$ \\
\hline Breastfeeding women & $27(46.5)$ \\
\hline Age (years) (mean \pm standard deviation) & $30.2 \pm 6.6$ \\
\hline Ethnicity of the mother & $44(75.9)$ \\
\hline White & $14(24.1)$ \\
\hline Non-white & $18(58.1)$ \\
\hline Trimester of pregnancy & $13(41.9)$ \\
\hline 2nd trimester & $25(92.5)$ \\
\hline 3rd trimester & $2(7.5)$ \\
\hline Mode of delivery & $7(29.6)$ \\
\hline Cesarean & $4(14.8)$ \\
\hline Vaginal & $3(11.1)$ \\
\hline Comorbid conditions* & $3(11.1)$ \\
\hline Diabetes & $2(7.4)$ \\
\hline Thrombosis & $8(25)$ \\
\hline Hypothyroidism & \\
\hline Cardiopathy & \\
\hline Chronic obstructive pulmonary disease & \\
\hline Other conditions & \\
\hline
\end{tabular}

Note: *Presence of underlying diseases in the patients.

were classified as secondary (298 [22.2\%] for the pregnant women, and 86 [17.0\%] for the breastfeeding women); and 26 were contraindicated (14 [1.0\%] for the pregnant women, and 12 [2.4\%] for the breastfeeding women).
A total of 175 different combinations of PDIs were identified in the prescriptions, with 6 combinations considered contraindicated ( 4 for the pregnant women, and 2 for the breastfeeding women), 55 considered important ( 40 for the pregnant women, and 28 for the breastfeeding women), 90 considered moderate ( 71 for the pregnant women, and 42 for the breastfeeding women), and 24 considered secondary (22 for the pregnant women, and 10 for the breastfeeding women). These PDIs were not actually observed in practice. - Table 2 shows the most frequent PDIs.

The main therapeutic classes and affected organs involved in the PDIs were those used for the nervous system (21; $26.6 \%$ ), cardiovascular system $(16 ; 20.3 \%)$, blood and the blood forming organs (13; $16.5 \%)$, anti-infectives for systemic use $(11 ; 13.9 \%)$ and alimentary system $(8 ; 10.1 \%)$.

\section{Risk Categorization of Drugs during Pregnancy and Breastfeeding}

Through the prescriptions, it was also possible to classify and identify the risk categorization of the drugs prescribed during pregnancy and breastfeeding, and the most frequently prescribed drugs that women were exposed to ( $\mathbf{- T a b l e ~} \mathbf{3}$ ).

A total of 127 types of drugs were prescribed by the doctors for the pregnant group, and 109 drugs were classified according to the FDA risk classification. A total of 18 drugs used in Brazil are not classified by the FDA, including dipyrone. The most frequently prescribed drugs were those classified as category $\mathrm{C}$.

Drugs with a negative risk-benefit (FDA category D or X) ratio were prescribed to 19 women (27.6\%): category D drugs were prescribed to 16 patients (66.0\%), and those classified as category $\mathrm{X}$ were prescribed to 3 patients (6.0\%). Drugs prescribed during the second trimester and classified as risk $\mathrm{D}$ and $\mathrm{X}$ were found in 14 prescriptions (12 belonging to pregnant women, and 2 belonging to breastfeeding women);

Table 2 Characteristics and frequency (\% in the study) of the prevalence of PDIs in the prescriptions

\begin{tabular}{|c|c|c|c|}
\hline \multicolumn{4}{|l|}{ Pregnant Women } \\
\hline Drugs involved & Severity & Warning & Total $(\%)^{*}$ \\
\hline dipyrone $x$ enoxaparin sodium & Important & Bleeding & $152(11.3)$ \\
\hline dipyrone $\mathrm{x}$ propranolol & Moderate & Decreased antihypertensive effect & $45(3.4)$ \\
\hline amlodipine $x$ dipyrone & Secondary & Gastrointestinal hemorrhage & $43(3.2)$ \\
\hline hydralazine x propranolol & Moderate & Increased risk of propranolol adverse effects & $39(2.9)$ \\
\hline furosemide $\mathrm{x}$ hydralazine & Moderate & Enhanced diuretic response to furosemide & $38(2.8)$ \\
\hline \multicolumn{4}{|l|}{ Breastfeeding Women } \\
\hline Drugs involved & Severity & Warning & Total $(\%)^{*}$ \\
\hline dipyrone $\mathrm{x}$ enoxaparin sodium & Important & Bleeding & $83(16.3)$ \\
\hline captopril x dipyrone & Moderate & Decreased antihypertensive efficacy & $29(5.7)$ \\
\hline amlodipine $x$ dipyrone & Secondary & Gastrointestinal hemorrhage & $24(4.7)$ \\
\hline fentanyl x midazolam & Important & Increased risk of CNS depression & $19(3.7)$ \\
\hline dipyrone $\mathrm{x}$ propranolol & Moderate & Decreased antihypertensive effect & $15(2.9)$ \\
\hline
\end{tabular}

Abbreviations: CNS, central nervous system; PDIs, potential drug interactions.

Notes: Severity classification and other information available in Micromedex (Truven Health Analytics, Ann Arbor, MI, US).

*Number of times in which the PDIs appeared in prescriptions. 
Table 3 Risk categorization of drugs used during pregnancy and breastfeeding, and some drugs implicated

\begin{tabular}{|l|l|l|l|}
\hline \multicolumn{4}{|l|}{ Pregnant Women } \\
\hline Risk categorization & Patients & Drugs (\%) & Type of drugs \\
\hline A & 25 & $3(2.8)$ & magnesium sulfate, levothyroxine, folic acid. \\
\hline B & 31 & $29(26.6)$ & enoxaparin sodium, methyldopa, dimenhydrinate, metoclopramide, ranitidine. \\
\hline C & 31 & $60(55.0)$ & omeprazole, hydralazine, dextrose, methadone, potassium chloride. \\
\hline D & 16 & $15(13.8)$ & phenytoin, lorazepam, midazolam, clonazepam, diazepam \\
\hline X & 3 & $2(1.8)$ & misoprostol, pravastatin. \\
\hline Breastfeeding Women & \multicolumn{3}{|l}{} \\
\hline Risk Categorization & Patients & Drugs (\%) & Type of drugs \\
\hline Very low risk & 27 & $58(71.6)$ & $\begin{array}{l}\text { enoxaparin sodium, simethicone, metoclopramide, bromopride, magnesium } \\
\text { sulfate. }\end{array}$ \\
\hline Low risk & 27 & $18(22.2)$ & dipyrone, tramadol, furosemide, ranitidine, dimenhydrinate. \\
\hline High risk & 4 & $4(4.9)$ & $\begin{array}{l}\text { chloramphenicol, nitroprusside, diazepam, dexchlorpheniramine, } \\
\text { prometazine. }\end{array}$ \\
\hline
\end{tabular}

during the third trimester, those drugs were found in 2 prescriptions of pregnant women, and in 1 prescription of a breastfeeding woman.

For the breastfeeding women, 94 different drugs were prescribed, and 81 were classified by the E-lactancia.org database. Some drugs, such as mineral oil, oxytocin, and pindolol, were not found in this database, and were not classified. Many of the most frequently prescribed drugs were classified as very low risk.

High risk drugs were found in 4 prescriptions of breastfeeding women (14.8\%) and low risk drugs were found in 24 prescriptions $(22.9 \%)$.

\section{Discussion}

Our study confirms that the prescriptions for pregnant and breastfeeding women hospitalized in an ICU, which mainly included anti-infective drugs for systemic use, and nervous system and cardiovascular system drugs, have a high incidence of PDIs. However. most of the drugs used by these women in the ICU did not present serious risks to their fetus and newborns.

The average age of the pregnant and breastfeeding patients who needed ICU admission was $\sim 30$ years, and a similar age was found in other studies in which the patients required admission to the obstetric ICU. ${ }^{20,21}$ In the present study, the most common cause of ICU admission was pregnancy-induced hypertensive disorders, which is in agreement with the study by Demirkiran et al, ${ }^{22}$ who analyzed 125 patients admitted to the ICU. Overall, few women become sufficiently ill to require hospitalization in an ICU, but the normal adaptive physiology of the pregnancy and the presence of a fetus or breastfeeding a newborn make these women different from other critically ill patients. Furthermore, the short ICU stay ( $\sim 5$ days) suggests that most of these patients did not have major complications. ${ }^{23,24}$
A total of $91 \%$ of the prescriptions presented at least one PDI, and all 4 classifications are present in the studied PDIs, (from contraindicated to secondary), and the most frequent interactions are moderate. The most recurrent moderate PDI observed was the interaction between dipyrone and captopril or propranolol. This PDIs have theoretical clinical relevancy, as caution in the use of both drugs is recommended: to monitor the antihypertensive efficacy and assess renal function periodically, but do not offer significant risks to the patients. Important PDIs were the second most prevalent, and the most frequent was the interaction between dipyrone and enoxaparin. The clinical management states the suspension of dipyrone or, if maintained, a continuous monitoring of bleeding episodes is necessary. ${ }^{7,15}$ Despite this clinical management, the choice of anticoagulant in this setting is based upon careful consideration of the maternal and fetal risks discussed with the patient. Considering this combination, which is classified as important, the symptoms should be monitored to avoid the possible adverse events described in the literature. ${ }^{7}$

Numerous drug classes are specially relevant for the high risk of interactions, and, in many cases, the management of the interaction would depend on the patients' clinical status, the routes and timing of drug administration, drug doses, or the response/lack of response to the current pharmacotherapy. ${ }^{25}$ Nervous system drugs were the most related with PDIs when grouped by ATC classification, and this high number can be justified considering that sedation and analgesia are essential components in the treatment of patients in intensive care. ${ }^{26}$ Drugs that act on the cardiovascular system were the second most related to PDIs when grouped by ATC classification. A study in a teaching hospital's ICU in Brazil demonstrated that the prescription of antihypertensive drugs is also considered the main cause of drug interactions among prescription drugs. ${ }^{27}$

Even though this research showed the high number of important, moderate and secondary PDIs found in the 
prescriptions (-Table 2 ), this does not necessarily correspond to the clinical relevancy, and the PDIs were not actually observed in practice at this Brazilian ICU. Thereby, even though some studies have reported drug interactions with some drug classes prescribed to pregnant and breastfeeding women, our findings prove that ours is a relevant study for this population in critical state, and it is important to support health professionals in making therapy decisions. ${ }^{28-30}$

Regarding the risk categorization for the pregnant women, most medications used were from category $C$, followed by category B, and similar results were found by a study conducted in a teaching hospital in Croatia in which the majority of pregnant women were exposed to category $C$ (56\%) and B (41\%) drugs. ${ }^{31}$ A small number of different drugs were responsible for the majority of prescriptions for category D drugs, as well as for category $X$ drugs during the analysis of the electronic prescriptions. Category D also comprehended a small number of different drugs, notably benzodiazepines (lorazepam, midazolam, clonazepam). It is clear that some category D drugs are being appropriately used considering the maternal benefit, such as antiepileptic drugs (phenytoin). ${ }^{31,32}$ In this research, the drugs classified as category $\mathrm{X}$ include misoprostol. Despite the use of misoprostol not being authorized by the FDA, this drug, classified as risk $\mathrm{X}$, is used for cervical ripening and labor induction, and its use is oriented by various guidelines. ${ }^{32,33}$ Its use in the puerperium is also safe and indicated in cases of postpartum hemorrhage and secondary to uterine atony. ${ }^{32}$ Other drugs classified by the FDA as risk X can be cited, such as pravastatin, which was prescribed for a pregnant patient during hospitalization as a substitute for omega $3 .^{21,34}$

The breastfeeding women included in the study were women declared able to breastfeed by the multidisciplinary team, even as they required intensive care. In the study period, 22 non-breastfeeding women admitted to the ICU were excluded. During the study, we observed that most of the drugs used by the breastfeeding women posed no serious risks to the newborn, since the "very low risk" category was the most prevalent, followed by the "low risk" category. Most drugs considered as "high risk" are being appropriately prescribed, taking into consideration the maternal benefit, but other drugs, such as diazepam, could be substituted by safer alternatives, which demonstrates that the clinical pharmacists of the ICU could provide direct patient care. ${ }^{18,34}$ There are no researches with a classification of drug safety during breastfeeding according to the E-lactancia database. $^{18}$

Among the various publications that report on the use of drugs during breastfeeding, the reference basic studies used are provided by the American Academy of Pediatrics (AAP). ${ }^{11,35,36}$ According to the AAP, certain classes of drugs can be problematic, either because of accumulation in the breast milk, or due to their effects on the nursing infant or mother. The most common drugs include pain medications, antidepressants, and drugs to treat substance/alcohol abuse or smoking. ${ }^{35}$ In the E-lactancia database, the classes of drugs that can be problematic to the newborn are the same drugs according to the AAP, the only thing that differs is the risk categorization.

The main strength of this study is its setting: the ICU of a Brazilian teaching hospital for women's healthcare, which treats pregnant and breastfeeding women. Moreover, this study had other advantages: the presence of electronic prescriptions in the teaching hospital, and the access to databases for evaluating the drugs presented in the prescriptions. A limitation of this study was that a pilot study to sample the calculation was not performed. However, taking into consideration the period of a year of study, and after the data analysis, this sample could be considered significant, because of the number of patients, the number of beds in the ICU, and the number of prescriptions analyzed.

\section{Conclusion}

This study demonstrated that there is a high incidence of PDIs in the pharmacotherapy prescribed to pregnant and breastfeeding women. This study also showed that most of the drugs used during pregnancy and breastfeeding at the ICU did not present serious risks to the fetus and the newborns.

\section{Declaration of Conflicts of Interest}

The authors declare no conflicts of interest with respect to the research, authorship, and/or publication of this article.

\section{Acknowledgments}

The researchers would like to thank the multidisciplinary team of the ICU, the pharmacy staff of the hospital, and the authors, for their support and collaboration during the research. Financial support from student fellowships was provided by Fundação de Amparo à Pesquisa do Estado de São Paulo (Foundation of Research Support of São Paulo State, FAPESP) (no: 2013/00812-5) and by Conselho Nacional de Desenvolvimento Científico e Tecnológico (National Council of Scientific and Technological Development, CNPq).

\section{References}

1 Hazelgrove JF, Price C, Pappachan VJ, Smith GB. Multicenter study of obstetric admissions to 14 intensive care units in southern England. Crit Care Med 2001;29(04):770-775

2 Chawla S, Nakra M, Mohan S, Nambiar BC, Agarwal R, Marwaha A. Why do obstetric patients go to the ICU? A 3-year-study. Med J Armed Forces India 2013;69(02):134-137

3 Okafor UV, Aniebue U. Admission pattern and outcome in critical care obstetric patients. Int J Obstet Anesth 2004;13(03):164-166

4 Quah TC, Chiu JW, Tan KH, Yeo SW, Tan HM. Obstetric admissions to the intensive therapy unit of a tertiary care institution. Ann Acad Med Singapore 2001;30(03):250-253

5 Loverro G, Pansini V, Greco P, Vimercati A, Parisi AM, Selvaggi L. Indications and outcome for intensive care unit admission during puerperium. Arch Gynecol Obstet 2001;265(04):195-198

6 Tatro DS. Drug Interaction Facts 2013: the authority on drug interactions. Philadelphia: Lippincott Williams \& Wilkins; 2012 
7 Rodrigues AT, Stahlschmidt R, Granja S, Falcão AL, Moriel P, Mazzola PG. Clinical relevancy and risks of potential drug-drug interactions in intensive therapy. Saudi Pharm J 2015;23(04): 366-370

8 Plaza J, Alamo M, Torres P, Fuentes A, López F. [Drug interactions and adverse events induced by drugs used in an intensive care unit]. Rev Med Chil 2010;138(04):452-460

9 Fantasia HC, Harris AL. Changes to pregnancy and lactation risk labeling for prescription drugs. Nurs Womens Health 2015;19 (03):266-270

10 Daw JR, Mintzes B, Law MR, Hanley GE, Morgan SG. Prescription drug use in pregnancy: a retrospective, population-based study in British Columbia, Canada (2001-2006). Clin Ther 2012;34(01): 239-249.e2

11 Chaves RG, Lamounier JA, César CC. Association between duration of breastfeeding and drug therapy. Asian Pac J Trop Dis 2011;1 (03):216-221

12 Dillon AE, Wagner CL, Wiest D, Newman RB. Drug therapy in the nursing mother. Obstet Gynecol Clin North Am 1997;24(03): 675-696

13 Lawrence RA. Breastfeeding. 5th ed. St Louis: Mosby; 1999

14 Riordan J. Anatomy and physiology of lactation. In: Riordan J, editors. Breastfeeding and human lactation. 3rd ed. Boston: Jones and Bartlett; 2005. p. 67-95

15 Micromedex Healthcare Series [Internet]. 2011 [cited 2016 Jun 4]. Available from: http://www.micromedexsolutions.com

16 World Health Organization [Internet]. Anatomical therapeutical chemical classification. 2015 [cited 2016 Jun 4]. Available from: http://www.whocc.no/atc_ddd_index/

17 Food and Drug Administration. FDA issues final rule on changes to pregnancy and lactation labeling information for prescription drug and biological products. Silver Spring: FDA; 2014

18 Marina Alta's Hospital. Pediatric Service. E-Lactancia [Internet] Compatibility of breastfeeding with pharmaceutical drugs and other products. 2014 [cited 2015 Jun 4]. Available from: http:// www.e-lactancia.org/ingles/inicio.asp

19 STROBE Statement. Strengthening the reporting of observational studies in epidemiology [Internet]. 2015 [cited 2016 Jun 4]. Available from: http://www.strobe-statement.org/

20 Laws P, Sullivan EA. Australia's mothers and babies 2007. Canberra: AIHW National Perinatal Statistics Unit; 2009

21 Lelong E, Pourrat O, Pinsard M, et al. Admission of women to an intensive care unit during pregnancy or the postpartum period: circumstances and prognosis. A retrospective series of 96 cases. Rev Med Interne 2013;34(03):141-147
22 Demirkiran O, Dikmen Y, Utku T, Urkmez S. Critically ill obstetric patients in the intensive care unit. Int J Obstet Anesth 2003;12 (04):266-270

23 Lapinsky SE. Cardiopulmonary complications of pregnancy. Crit Care Med 2005;33(07):1616-1622

24 Mirghani HM, Hamed M, Ezimokhai M, Weerasinghe DS. Pregnancy-related admissions to the intensive care unit. Int J Obstet Anesth 2004;13(02):82-85

25 Rivkin A, Yin $\mathrm{H}$. Evaluation of the role of the critical care pharmacist in identifying and avoiding or minimizing significant drug-drug interactions in medical intensive care patients. J Crit Care 2011;26(01):104.e1-104.e6

26 Gommers D, Bakker J. Medications for analgesia and sedation in the intensive care unit: an overview. Crit Care 2008;12(Suppl 3):S4

27 Reis AMM, Cassiani SHB. Adverse drug events in an intensive care unit of a university hospital. Eur J Clin Pharmacol 2011;67(06): 625-632

28 Olivier JD, Åkerud H, Sundström Poromaa I. Antenatal depression and antidepressants during pregnancy: unraveling the complex interactions for the offspring. Eur J Pharmacol 2015;753:257-262

29 Ngan Kee WD, Khaw KS, Ng FF, Ng KK, So R, Lee A. Synergistic interaction between fentanyl and bupivacaine given intrathecally for labor analgesia. Anesthesiology 2014;120(05):1126-1136

30 Krauss GL, Brandt J, Campbell M, Plate C, Summerfield M. Antiepileptic medication and oral contraceptive interactions: a national survey of neurologists and obstetricians. Neurology 1996; 46(06):1534-1539

31 Erdeljić V, Francetić I, Makar-Ausperger K, Likić R, Radacić-Aumiler M. Clinical pharmacology consultation: a better answer to safety issues of drug therapy during pregnancy? Eur J Clin Pharmacol 2010;66(10):1037-1046

32 ACOG Committee on Practice Bulletins - Obstetrics. ACOG Practice Bulletin No. 107: Induction of labor. Obstet Gynecol 2009;114 (2 Pt 1):386-397

33 Leduc D, Biringer A, Lee L, Dy J; Society of Obstetricians and Gynaecologists of Canada. Induction of labour. J Obstet Gynaecol Can 2013;35(09):840-860

34 Newton ER, Hale TW. Drugs in breast milk. Clin Obstet Gynecol 2015;58(04):868-884

35 Sachs HC; Committee On Drugs. The transfer of drugs and therapeutics into human breast milk: an update on selected topics. Pediatrics 2013;132(03):e796-e809

36 Amir LH, Pirotta MV, Raval M. Breastfeeding-evidence based guidelines for the use of medicines. Aust Fam Physician 2011; 40(09):684-690 